Supporting Information

\title{
Sensing Capabilities of Colloidal Gold Monolayer Modified with a Phenylboronic Acid-Carrying Polymer Brush
}

Hiromi Kitano, * Yasutaka Anraku, and Hiroaki Shinohara

Department of Chemical and Biochemical Engineering,

University of Toyama, Toyama, 930-8555 Japan.

* To whom correspondence should be addressed.

Preparation of Brush-forming Polymer. Cys-BDC (33.0 mg), APBA (20.3 mg), DMAPMA (1.8 $\mathrm{mg}$ ) and $N, N, N^{\prime}, N^{\prime}$-tetraethylthiuram disulfide (TD, capping reagent, $33.0 \mathrm{mg}$ ) were dissolved in a mixture of anhydrous tetrahydrofuran (THF) and methanol (1:1), and, after passing $\mathrm{N}_{2}$ gas for several minutes, photo-irradiated in a quartz cell with a high-pressure mercury lamp (UI-501C, 250 $\mathrm{W}$, Ushio, Tokyo, Japan) from a distance of $25 \mathrm{~cm}\left(3.0 \times 10^{14}\right.$ quanta. $\left.^{-1}\right)$ at $35{ }^{\circ} \mathrm{C}$ for $6 \mathrm{~h}$. The phenylboronic acid-carrying copolymer was purified by ultrafiltration (membrane, Amicon YM1; exclusion limit, $10^{3}$ ), and finally lyophilized in the dark (Cys-Poly(APBA-co-DMAPMA), Polymer-2, $8.3 \mathrm{mg}$; Table 1 in the text). The chemical structures and the molecular weights of the copolymers were analyzed by ${ }^{1} \mathrm{H}-\mathrm{NMR}$ (DX-400 , JEOL, Tokyo, Japan). Polymers composed of different monomer residues were also prepared using the similar procedure (Table 1).

Preparation of Gold Colloids. All glassware used for preparation of the colloids was thoroughly washed with aqua regia $\left(3: 1 \mathrm{HCl}-\mathrm{HNO}_{3}\right)$, and rinsed extensively with water. Gold colloids were prepared by the reduction of $\mathrm{HAuCl}_{4}$ with sodium citrate in water at $100{ }^{\circ} \mathrm{C}$ as previously reported. ${ }^{\mathrm{S}-1}$ The average hydrodynamic diameter of the gold colloids was estimated to be $20 \mathrm{~nm}$ by the dynamic light scattering technique (DLS-7000, Otsuka Electronics, Hirakata, Osaka, Japan; light source, He-Ne laser $632.8 \mathrm{~nm}$ ). 
Fixation of Colloidal Gold Monolayer on a Glass Substrate. A cover glass (thickness, $160 \mu \mathrm{m}$; Matsunami Glass, Osaka, Japan) cut into $13.0 \times 24 \mathrm{~mm}$ pieces was used for the fabrication of the colloidal Au monolayer. The glass substrates were cleaned by sonication for $2 \mathrm{~h}$ in water containing a $3 \%$ detergent (Contaminon N, Wako Pure Chemicals) and washed thoroughly with water. The substrates were further cleaned in conc. $\mathrm{HNO}_{3}$ for $4 \mathrm{~h}$, washed thoroughly with water and, after cleaning using sonication for $2 \mathrm{~min}$, dried in a drying oven at $70{ }^{\circ} \mathrm{C}$ overnight. The substrates were immersed in a $10(\mathrm{v} / \mathrm{v}) \%$ APTES aqueous solution for $60 \mathrm{~min}$, rinsed with water and sonicated for $20 \mathrm{~s}$, and finally dried at $70{ }^{\circ} \mathrm{C}$ for $3 \mathrm{~h}$. The amine-terminated glass cover slips were subsequently immersed into a colloidal gold solution for $6 \mathrm{~h}$ to form a self-assembled monolayer of Au colloids.

AFM Images. The immobilized Au colloids on the glass substrate were imaged by an atomic force microscope (AFM, Multimode Nanoscope, Seiko Instruments, Tokyo, Japan) in tapping mode in air using a standard $\mathrm{Si}_{2} \mathrm{~N}_{4}$ cantilever (Figure $\left.\mathbf{S}-\mathbf{1}\right)$.

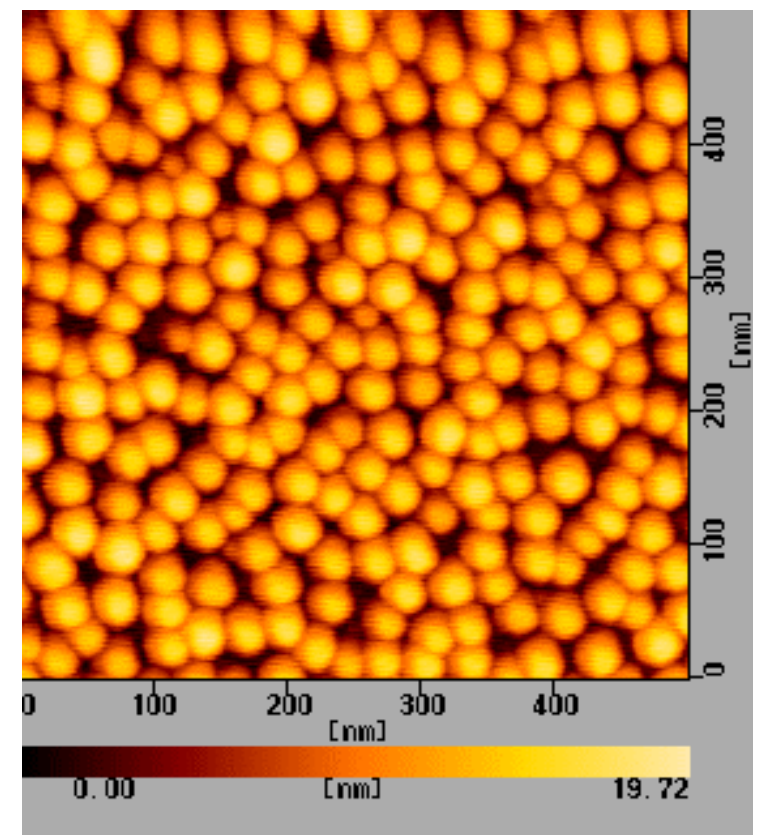

Figure S-1. Photo of the colloidal Au-fixed glass substrate taken by AFM. For the modification with amino groups, the cover glass was incubated in a $10 \%$ APTES aqueous solution for 60 min. 
Functionalization of Colloidal Gold-fixed Glass Substrate. The colloidal Au-fixed glass substrates were modified with various disulfide-carrying polymers by immersion in a $0.5 \mathrm{mg} / \mathrm{mL}$ polymer solution for $4 \mathrm{~h}$, and subsequent extensive rinsing with water. The polymer brush-carrying glass substrates were stored in water until the absorption measurements.

Absorption Measurements. A UV-visible-near-infrared spectrophotometer (Lambda 19 UV/VIS/NIR spectrophotometer, Perkin Elmer) was used to measure the absorbance of the immobilized Au colloids on a glass substrate placed in a quartz cell (light path length, $10 \mathrm{~mm}$ ). Spectra of the device were obtained in transmission mode over a range of $350-850 \mathrm{~nm}$ at $25{ }^{\circ} \mathrm{C}$ (controlled by a Peltier device, PTP-1 Peltier System, Perkin Elmer) (Figure S-2). In the experiments using various kinds of proteins, carbonate buffer $\left(\left[\mathrm{Na}_{2} \mathrm{CO}_{3}\right]=50 \mathrm{mM}, \mathrm{pH} 11.2\right)$ was used. For the evaluation of critical flocculation concentration (CFC), the gold colloid dispersion was added to aqueous solution of $\mathrm{NaCl}$ at various concentrations using a polyethylene mixing-rod. The way of mixing was always the same in order to avoid the "orthokinetic effect". The initial absorbance change at $550 \mathrm{~nm}$ was followed by the spectrophotometer (Figure S-3). Above CFC there is no electric repulsion between the particles, which results in a rapid coagulation where the process is diffusion-controlled. The value of the CFC for the gold colloids examined in this work was $4.0 \times 10^{-2} \mathrm{M}$. 


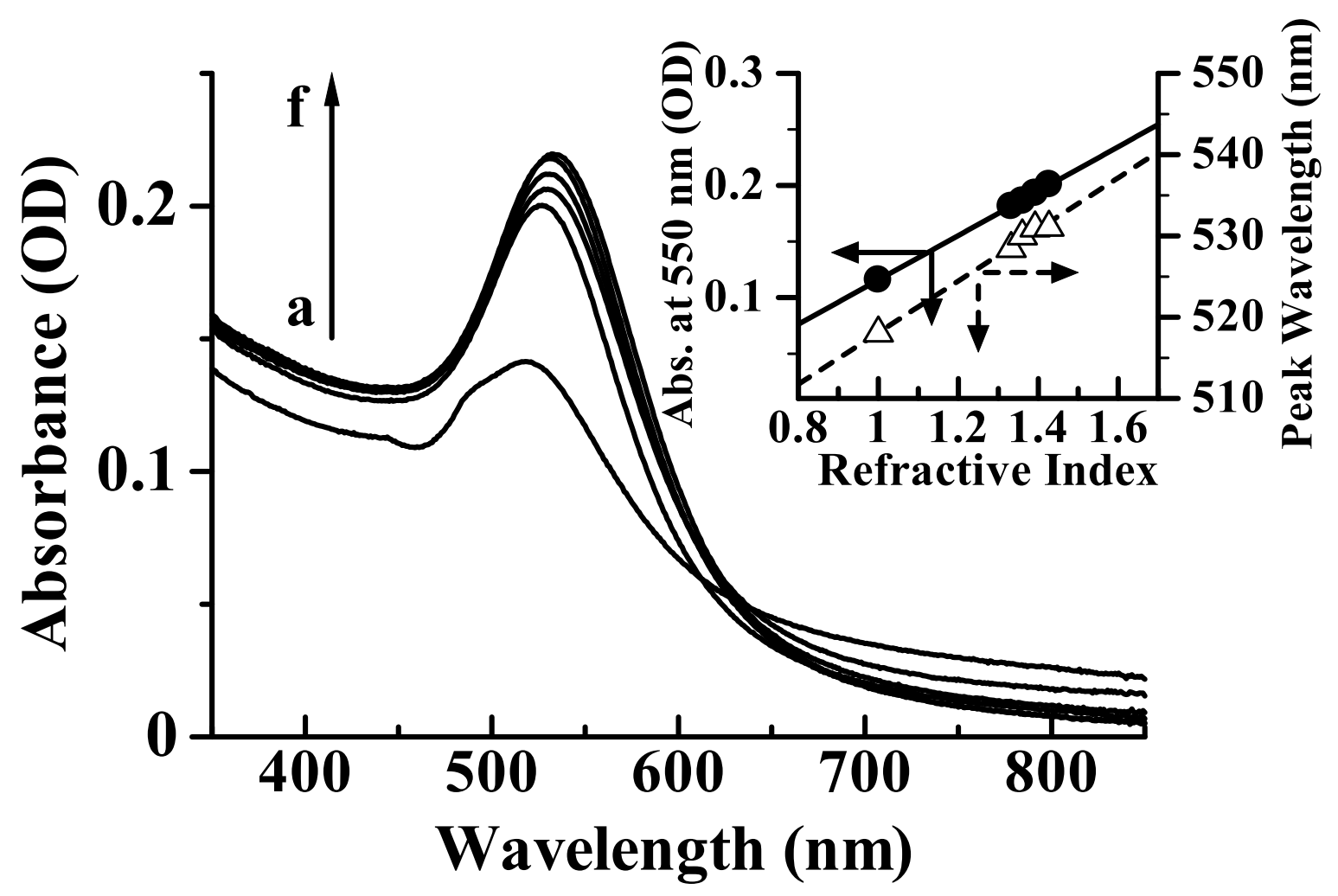

Figure S-2. Absorbance spectra of Polymer-1-modified Au colloids on glass immersed in various solvents at $25^{\circ} \mathrm{C}$ : (a) air ( $\left.\mathrm{n}=1\right)$; (b) water ( $\left.\mathrm{n}=1.332\right)$; (c) ethanol $(\mathrm{n}=1.360)$; (d) $3: 1(\mathrm{v} / \mathrm{v})$ ethanol-toluene ( $\mathrm{n}=1.392) ;(\mathrm{e}) 1: 1(\mathrm{v} / \mathrm{v})$ ethanol-toluene $(\mathrm{n}=1.427) ;(\mathrm{f}) 1: 3(\mathrm{v} / \mathrm{v})$ ethanol-toluene $(\mathrm{n}=1.462)$. 


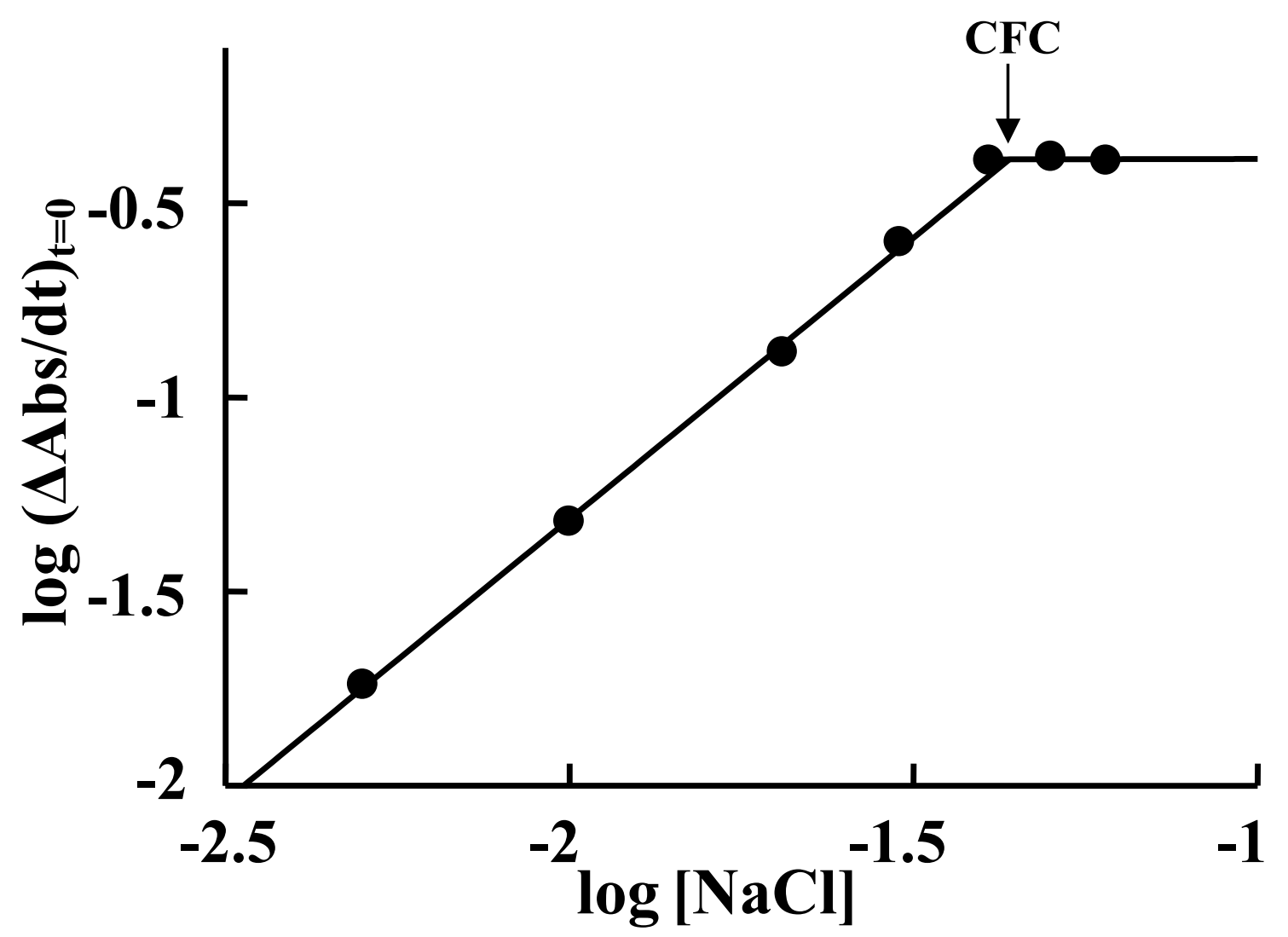

Figure S-3. Plots of the initial absorbance change $(\Delta \mathrm{Abs} / \mathrm{dt})_{\mathrm{t}=0}$ versus the concentration of sodium chloride. 
Kinetic Analysis of Protein Adsorption. Let us consider the association equilibrium between a protein (A) and a ligand (B) and their complex (C) (S-1).

$$
\mathbf{A}+\mathbf{B} \underset{k_{-1}}{\stackrel{k_{1}}{\longrightarrow}} \mathbf{C}
$$

When the initial concentration of $\mathbf{A}$ and $\mathbf{B}$ are $a$ and $b$, respectively,

the equilibrium state can be given as follows,

$$
k_{1}\left(a-x_{\mathrm{e}}\right)\left(b-x_{\mathrm{e}}\right)=k_{-1} x_{\mathrm{e}}
$$

where $x_{\mathrm{e}}$ is the concentration of the complex $\mathbf{C}$ at equilibrium.

If $a$ is much larger than $b$,

$$
k_{1} a\left(b-x_{\mathrm{e}}\right)=k_{-1} x_{\mathrm{e}}
$$

Then, $x_{\mathrm{e}}$ can be given as follows,

$$
x_{\mathrm{e}}=k_{1} a b /\left(k_{1} a+k_{-1}\right)
$$

The double reciprocal plot $\left(1 / x_{\mathrm{e}}\right.$ vs. $1 / a$, Figure S-4) is indicated by the following equation.

$$
1 / x_{\mathrm{e}}=(1 / b)+(1 / a)(1 / b)\left(k_{-1} / k_{1}\right)
$$

Meanwhile, the relaxation curve of the concentration of complex $\mathbf{C}(x$, Figure $\mathbf{S - 5})$ is given by the following equation,

$$
\Delta x=x_{\mathrm{e}} \exp \left\{-\left(k_{1} a+k_{-1}\right) t\right\}
$$

The difference between $x_{\mathrm{e}}$ and $\Delta x(y)$ is given as follows.

$$
\begin{aligned}
y & =x_{\mathrm{e}}-\Delta x=x_{\mathrm{e}}\left[1-\exp \left\{-\left(k_{1} a+k_{-1}\right) t\right\}\right] \\
& =x_{\mathrm{e}}\{1-\exp (-D t)\}
\end{aligned}
$$

where $D$ denotes $k_{1} a+k_{-1}$. Then,

$$
d y / d t=x_{\mathrm{e}} D \exp (-D t)
$$

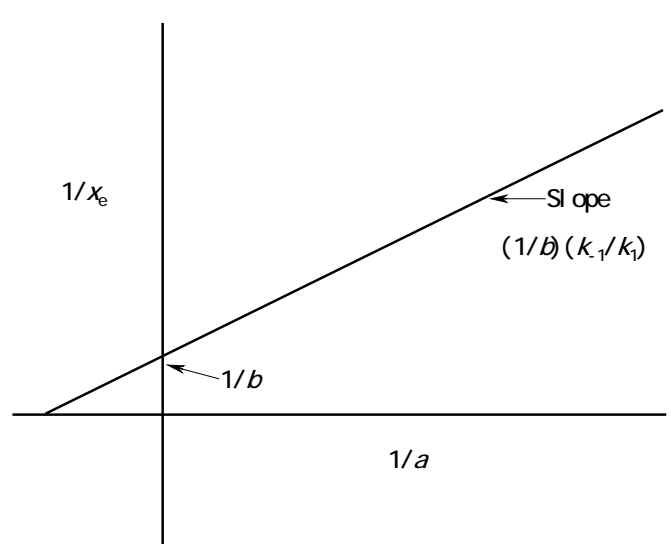

Figure S-4. Relationship between $1 / x_{\mathrm{e}}$ and $1 / a$ (equation S-5).

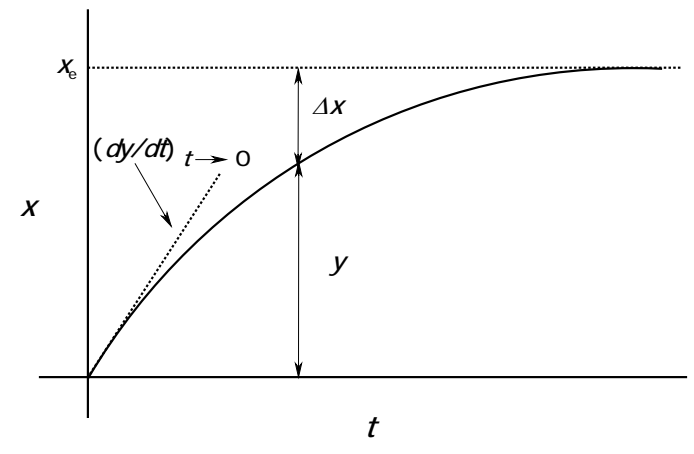

Figure S-5. Relaxation curve for the concentration of complex C (equation S-6). 
Therefore,

$$
(d y / d t)_{\mathrm{t} \rightarrow 0}=x_{\mathrm{e}} D=k_{1} a b
$$

The plot of S-5 $\left(1 / x_{\mathrm{e}}\right.$ vs. $\left.1 / a\right)$ has a slope of $(1 / b) \times\left(k_{-1} / k_{1}\right)$

(Figure S-4), and that of S-9 $\left((d y / d t)_{\mathrm{t} \rightarrow 0}\right.$ vs. $a$, Figure S-6) has a slope of $k_{1} b$. From these plots, the values of $k_{1}, k_{-1}$ and $K_{\text {assoc }}$ could unequivocally be determined.

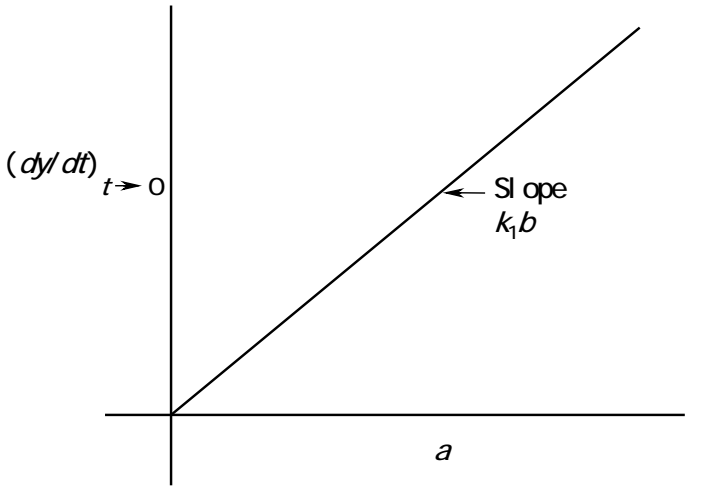

The $a, b$ and $x$ correspond to [OVA], [APBA] and [Complex], respectively, in the equations (3) and (4) in the Figure S-6. Relationship between the initial slope vs. the concentration of protein A (a) (equation S-9). text.

\section{Preparation of Biotinylated Human Serum Albumin (Scheme S-1).}

Human Serum Albumin (HSA, $50 \mathrm{mg}$ ) was dissolved in phosphate buffer solution ( $\mathrm{pH} 7.4,10 \mathrm{mM}$ ) at concentration of $10 \mathrm{mg} / \mathrm{mL}$. Sulfosuccinimidyl-6-(biotinamido)hexanoate (Sulfo-NHS-LC-biotin, Pierce, $10 \mathrm{mg}$ ) was dissolved in Milli-Q water at a concentration of $20 \mathrm{mg} / \mathrm{mL}$. The Sulfo-NHS-LC-biotin solution was added to the HSA solution $(5 \mathrm{~mL})$, and incubated for $60 \mathrm{~min}$ at room temperature. Unreacted biotinylation reagent and reaction by-products were removed by gel filtration using a column of Sephadex G-10, and the biotinylated HSA was finally lyophilized (32.5 $\mathrm{mg}$ ). The degree of substitution of biotinyl groups in the HSA molecule was determined to 1.4 by the colorimetry with 4'-hydroxyazobenzene-2-carboxylic acid (HABA). ${ }^{\mathrm{S}-2}$ 
<smiles>[NH3+]OC(=O)C1C(OC(=O)CCCCCNC(=O)CCCCC2SCC3NC(=O)NC32)C(=O)CC1S(=O)(=O)O[NH3+]</smiles><smiles>CC(C)CCCCCCCCCCCCCC(=O)NCCCCCC(=O)NC1CCCCCCCC1</smiles>

Scheme S-1. Preparation of Biotinylated Human Serum Albumin

\section{References}

(S-1) Nath, N.; Chilkoti, A. Anal. Chem. 2002, 74, 504.

(S-2) Hermanson, G. T. In Bioconjugate Technique: Academic Press: San Diego, 1996. 